\title{
LO SUBJETIVO EN EL JUICIO DE IMPUTACIÓN OBJETIVA: ¿APORÍA TEÓRICA?
}

\author{
Luis Emilio Rojas Aguirre*
}

A Juan Bustos Ramírez

\begin{abstract}
RESUMEN
El presente trabajo indaga en los orígenes teóricos de la categoría jurídico-penal de la imputación objetiva. Sintetiza los planteamientos originales de la teoría de la imputación objetiva, mostrando que el grado de elaboración contenido en ellos es mayor del que se suele reconocer y valorar. Luego, y a partir de dichos planteamientos originales, se aproxima a un problema específico que atañe a la existencia misma de la imputación objetiva como categoría de la dogmática penal, cual es el de la consideración y valoración de aspectos subjetivos en sede de imputación objetiva.
\end{abstract}

DERECHO PENAL - IMPUTACIÓN OBJETIVA - NORMA PENAL

What is subjective in an objective imputation judgement: A theoretical aporia?

\begin{abstract}
The present work searches for the theoretical origins of the criminal-legal concept of objective imputation. It summarizes the original proposals of the theory of objective imputation, showing that their degree of development is higher than is generally recognized and valued. Then, and from these original approaches, the paper addresses a specific problem that concerns the very existence of the objective imputation as a category in criminal science: the consideration and assessment of the subjective aspects in objective imputation.
\end{abstract}

\section{CRIMINAL LAW - OBJECTIVE IMPUTATION - CRIMINAL NORMS}

* Abogado, Master en Derecho, Profesor de Derecho Penal en la Universidad Alberto Hurtado, Santiago deChile.lurojas@uahurtado.cl

Artículo recibido el 5 de mayo de 2009 y aceptado para su publicación por el Comité Editorial el 28 de mayo de 2010. 


\section{INTRODUCCIÓN}

L a categoría de la imputación objetiva es creada en un intento por superar la causalidad como elemento fundante del injusto. De ahí que se ubique sistemáticamente en la parte objetiva del injusto, en contraste con el aspecto subjetivo del mismo. Esta decisión sistemática obliga a concebir esta categoría en términos objetivos, con total prescindencia de la valoración de aspectos subjetivos. Sin embargo, cuando las bases originales de la teoría de la imputación objetiva se someten a revisión, se puede observar que dicha contraposición no es absoluta. Esta constatación obliga a recurrir a planteamientos teóricos que fundan el juicio de imputación objetiva en bases nuevas, con lo cual emprenden una auténtica desarticulación y reconstrucción de la teoría de la imputación objetiva ${ }^{1}$.

\section{BASES TEÓRICAS DE La IMPUTACión OBJETIVA}

Las bases originales de la teoría de la imputación objetiva son fundamentalmente tres: el escrito de Dissertation de Karl Larenz, del año $1927^{2}$, el artículo sobre causalidad e imputación objetiva de Richard Honig, de $1930^{3}$ y las reflexiones de Claus Roxin sobre la problemática de la imputación en Derecho penal, del año $1970^{4}$. A continuación se sintetiza cada uno de estos planteamientos, para luego abordar la discusión sobre el lugar y valoración de aspectos subjetivos en el juicio de imputación objetiva.

${ }^{1}$ En esta línea se inscribe el planteamiento de Juan Bustos Ramírez sobre imputación objetiva, "Imputación objetiva: cuestiones metodológicas y sistemáticas", en: Obras Completas, ARA Editores, Lima 2004, Tomo II (artículo publicado originalmente en: Gedächtnisschrift für Armin Kaufmann, Köln, 1989, 213 y ss.) y Manual de Derecho Penal, Parte General, 4. ed., PPU, Barcelona, 1994, a quien se dedica el presente trabajo al cumplirse dos años de su muerte.

${ }^{2}$ Hegels Zurechnungslehre und der Begriff der objektiven Zurechnung, Diss., Göttingen, 1927 (en adelante: Hegels Zurechnungslehre); Kaufmann, A., “'Atribución objetiva' en el delito doloso?”, en: Anuario de Derecho Penal y Ciencias Penales, Tomo XXXVIII, 1985, p. 808 (en adelante: ADPCP), afirma que Larenz desarrolló su doctrina de la imputación objetiva para el Derecho Civil.

3 "Kausalität und objektive Zurechnung", en: Festgabe für Reinhard von Frank, Hegler, A. (coord.), Scientia Verlag, Tübingen, 1930, Tomo I (en adelante: FS Frank); Maiwald, M., "Zur strafrechtssystematischen Funktion des Begriffs der objektiven Zurechnung”, en: Festschrift für Koichi Miyazawa, Nomos, Baden-Baden, 1995 (en adelante: FS Miyazawa), p. 465, 470, reconoce a Honig como iniciador e introductor del concepto de imputación objetiva en el Derecho penal, quien habría recibido el impulso en esta dirección del escrito “orientado al derecho civil” de Larenz.

4 “Gedanken zur Problematik der Zurechnung im Strafrecht”, en: Festschrift für Richard M. Honig, Otto Schwartz \& Co., Göttingen, 1970 (en adelante: FS Honig); posteriormente Jakobs, G., Strafrecht, Allgemeiner Teil, 2. ed., De Gruyter, Berlin, 1993, 7/1 y ss., se convierte en uno de los principales exponentes de esta teoría (en adelante: Strafrecht, AT). 


\section{a) Origen en el planteamiento filosófico de Karl Larenz}

El planteamiento de Larenz tiene una clara orientación filosófica. Larenz construye su concepto de imputación objetiva sobre la base del sistema filosófico de $\mathrm{Hegel}^{5}$. De éste, releva los presupuestos fundamentales de la imputación que son el espíritu y la voluntad $^{6}$. El espíritu es el movimiento de volverse otro, esto es, objeto de sí mismo, y superar esa otredad (Anderssein) ${ }^{7}$. La naturaleza es el espíritu en su otredad, el momento de la oposición, es la contradicción no resuelta del sí mismo (Selbst), no ser sí mismo. La naturaleza se caracteriza por la necesidad externa y la casualidad ${ }^{8}$. Esa contradicción se supera en el espíritu, que se resuelve a ser sí mismo y cuya esencia no es más la necesidad externa, lo casual, sino necesidad interna ${ }^{9}$. La voluntad siempre busca algo, un fin determinado $^{10}$. El fin es inicialmente una representación del sujeto, algo pensado. Sin embargo, esta representación no es la de un objeto que simplemente está ahí, sino la de algo a realizar mediante la actividad del sujeto ${ }^{11}$. La voluntad se relaciona con el fin de un modo distinto a la relación causa-efecto; no se vincula a éste como a algo ajeno, sino que se lo apropia. La voluntad no provoca el fin como la causa el efecto, sino que realiza algo que le es propio, en el que se expresa a sí misma. La cadena causal se vuelve medio para el fin ${ }^{12}$. En éste, se supera la causalidad. Causa y efecto, que en la naturaleza están indiferentes una junto al otro, se unen en el fin. Esa relación indiferente entre causa y efecto responde a la mera casualidad $^{13}$, la que es superada en el fin. La realización de éste no es el paso de uno en otro, como en la relación de causa y efecto, sino realización de sí mismo en otro; implica la superación de aquella relación entre casualidad y necesidad externa propia de la naturaleza. El fin alcanzado no es algo ajeno y casual para la voluntad, sino su hecho propio ${ }^{14}$.

La imputación es, en el sistema de Hegel, el reconocimiento del individuo como sujeto y espíritu por el derecho, que valora su hacer como un hecho de libertad. Acción es expresión de la voluntad subjetiva; dolo es la correspondencia entre voluntad interior

${ }^{5}$ Larenz, K., Hegels Zurechnungslebre, p. 2, también recurre al sistema de Kant, que sintetiza en: ob. cit., pp. 17 y ss.

${ }^{6}$ Larenz, K., ob. cit., pp. 30 y ss.

${ }^{7}$ Larenz, K., ob. cit., p. 32.

${ }^{8}$ Larenz, K., ob. cit., p. 33 y s.

${ }^{9}$ Larenz, K., ob. cit., p. 34.

${ }^{10}$ Larenz, K., ob. cit., p. 41.

${ }^{11}$ Larenz, K., ob. cit., p. 42.

${ }^{12}$ Larenz, K., ob. cit., p. 43.

${ }^{13}$ En la lengua española, las palabras "causalidad" y "casualidad" se distinguen sólo por la posición de una letra; ello no ocurre en la lengua alemana, donde se usan dos palabras distintas: Kausalität = causalidad y Zufälligkeit = casualidad.

${ }^{14}$ Larenz, K., ob. cit., p. 44, se distingue entre la voluntad como mero arbitrio, que sólo domina los instintos, de la voluntad libre, que pertenece al reino de la libertad, a la realidad de la moral y del derecho, el espíritu objetivo, ob. cit., pp. 45 y ss. 
y exterior ${ }^{15}$. Pues bien, la imputación responde la pregunta sobre qué se puede atribuir al sujeto como su acción, por la cual se hace responsable. Esta pregunta puede plantearse primeramente con independencia de una valoración moral o jurídica de la acción; asimismo, no exige un juicio de valor, en especial no supone considerar atributos individuales del autor, sino que es sólo un juicio sobre una relación objetiva. "Este juicio queremos denominarlo imputación objetiva", dice Larenz, con lo cual ejecuta un auténtico acto de bautizo de esta teoría ${ }^{16}$. Este juicio nos dice si un suceso es hecho de un sujeto. Acción es la unidad de la voluntad subjetiva y del ser exterior producido mediante ésta ${ }^{17}$. Casual en la acción es todo aquello que es ajeno a la voluntad, aquello que no fue consciente, donde no existe correspondencia entre voluntad interior y exterior. Aquí pertenecen las circunstancias externas respecto de las cuales la acción influye, pero que el actor no ha previsto completamente, como en el caso de un sujeto que aprieta el gatillo de una escopeta que creía descargada, cuando estaba cargada, o del cazador que dispara a un hombre creyendo que era un animal salvaje. Dado que estas circunstancias externas no eran conscientes, deviene un hecho distinto del buscado, por lo que no puede ser imputado. Pertenece a la mera casualidad, no es un hecho propio del sujeto ${ }^{18}$. Es aquí donde Larenz reprocha a Hegel no haber contemplado las acciones imprudentes. El filósofo cometería el error de desconocer que el saber mismo es hecho de libertad, por lo que también el no-saber puede ser imputado, en tanto no es casual para el sujeto, sino que es obra de su libertad, al ser posible para el sujeto el conocimiento de esas circunstancias externas ${ }^{19}$.

Aquello que sólo es causado es una consecuencia meramente casual del hecho ${ }^{20}$. Sólo pueden ser imputadas aquellas consecuencias que configuran una unidad con la acción, en tanto ella -la unidad- es dominada mediante el fin. La dialéctica de la imputación objetiva consiste en que las consecuencias casuales y propias del hecho se unen unas a las otras. El fin resuelve esta contradicción, en tanto es la unidad que le da un carácter general a aquella variedad de relaciones externas, carácter que constituye la esencia del hecho determinado ${ }^{21}$. La solución de aquella oposición entre casualidad y necesidad depende de una reflexión sobre la relación del acontecimiento con la voluntad del autor, que vincula la multiplicidad de los elementos causales en una unidad teleológica. Ello muestra que no se puede prescindir del momento subjetivo de la acción, sólo que debe ser entendido como una unidad objetiva. El lado objetivo de la imputación contiene ya en sí una referencia al sujeto, a la voluntad como unidad abarcadora. Recién una re-

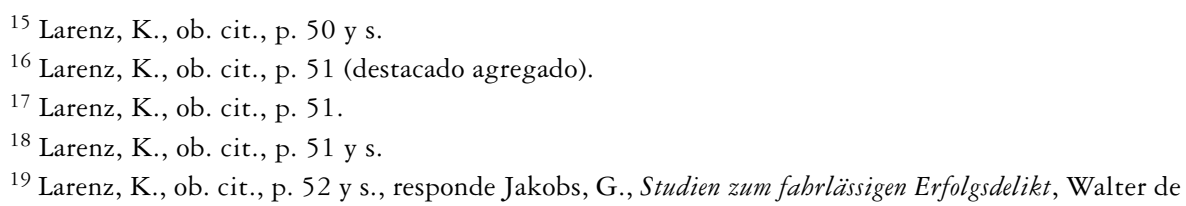
Gruyter, Berlin 1972, p. 42: lo determinante no es si el saber es un hecho de libertad, sino más bien qué "libertad" posibilita un saber presente o alcanzable.

${ }^{20}$ Larenz, K., ob. cit., p. 53 y s.;

${ }^{21}$ Larenz, K., ob. cit., p. 54. 
flexión más profunda y amplia sobre el momento subjetivo de la imputación conduce a la observación de peculiaridades individuales del sujeto, de la imputabilidad subjetiva. Es decir, la imputación objetiva se completa con una imputación subjetiva, que comprende las capacidades, la comprensión y la intención individual del actor. Sin embargo, la imputación subjetiva encuentra su frontera en el sentido objetivo del hecho, determinado por la imputación objetiva ${ }^{22}$.

Sobre la base de estas premisas, Larenz cuestiona un concepto de hecho basado en la causalidad. Todos los intentos de los juristas de concebir el hecho como mera relación de causalidad, de entender la imputación al hecho como juicio causal, estaban condenados al fracaso, sentencia Larenz. Ejemplo: A envía a B durante una tormenta a una colina cubierta de un bosque con árboles altos, con la esperanza de que un rayo lo alcance. Esto acontece. El sentido de la pregunta no puede ser, entonces, si A ha causado la muerte de $\mathrm{B}$, sino si ésta puede serle imputada objetivamente como su hecho propio, o si ésta es consecuencia de un encuentro completamente casual. Esta cuestión no es una mera pregunta de causalidad, sino un problema de imputación ${ }^{23}$. Imputación al hecho significa relación del acontecimiento con la voluntad ${ }^{24}$. La imputación objetiva y no sólo la imputación a la culpabilidad supone el concepto de persona como sujeto libre que se autodetermina ${ }^{25}$. El hecho del sujeto no es algo que le es ajeno e indiferente, sino expresión de su esencia. Por eso el hecho no es una mera modificación, una secuencia de causas y efectos, sino una unidad, un todo. El sujeto no es el primer elemento de una cadena de causas y efectos, sino el principio configurador; principio como comienzo y como regla del acontecimiento ${ }^{26}$.

La voluntad se realiza en el hecho. Mediante la capacidad de definir fines y de realizarlos, de darle al curso causal la dirección hacia un objetivo, quizás lejano, pero consciente y querido, de servirse del mismo, la voluntad domina el acontecimiento natural y lo convierte en su propio hecho ${ }^{27}$. La imputación como juicio sobre el hecho no es por tanto un juicio causal, sino teleológico. El concepto de fin no debe entenderse subjetiva, sino objetivamente; no sólo debe imputarse aquello que era consciente y querido, sino también aquello que era consciente y que podía ser abarcado por la voluntad, que era posible objeto de la voluntad. El hecho es entonces autorrealización de la voluntad y la imputación es el juicio que vincula al hecho con la voluntad ${ }^{28}$.

En este sentido, Larenz entiende por voluntad el yo que interviene en el mundo exterior actuando, en tanto define fines y los realiza; acción es expresión de la voluntad,

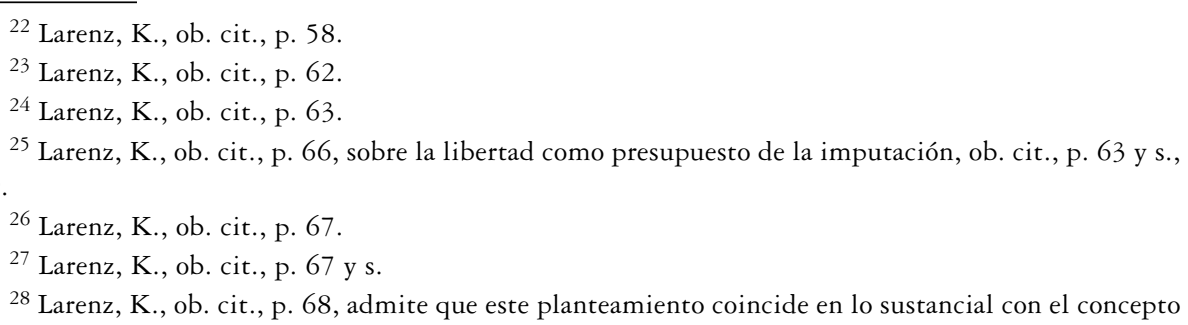
de acción sostenido por los hegelianos en la ciencia del Derecho penal, ob. cit., p. 69 y ss. 
esto es, una actividad corporal que es dirigida por la voluntad; y becho es la realización completa de la voluntad, esto es, tanto la actividad inmediata del sujeto - la acción- como el acontecimiento posterior - las consecuencias de la acción-, en la medida en que éste se encuentra en una conexión teleológica con aquél, que es dominado por la voluntad. De ahí que se hable de causalidad de la voluntad. Esta supone, por una parte, la capacidad de un sujeto de prever el curso causal, de reconocer el efecto de determinadas causas, esto es, el momento del conocimiento, y, por otra, la capacidad de intervenir, en base a ese conocimiento, en el curso causal y darle la dirección deseada. El hombre se convierte en autor, en tanto es persona, y su fin se arraiga en la libertad de su voluntad ${ }^{29}$. Distinguir el becho propio de la casualidad es la tarea de la imputación objetiva. Esta tarea debe ejecutarse en base al conocimiento de la autenticidad de la causalidad de la voluntad como causalidad final ${ }^{30}$. La imputación objetiva no se reduce a lo efectivamente previsto por el autor, sino que convierte la posibilidad de la previsión en principio de imputación ${ }^{31}$. Las consecuencias del hecho pueden ser casuales en relación al sujeto actuante, pues el encuentro de las distintas circunstancias puede ocurrir con independencia de su voluntad. No se trata entonces de la pregunta, si la consecuencia como tal era posible, sino de si su previsión le era posible al autor; pues, esta posibilidad del conocimiento es la posibilidad propia del sujeto ${ }^{32}$. Las consecuencias, cuya previsión le era posible al autor, caen en el ámbito de su voluntad, lo cual justifica su imputación ${ }^{33}$. Sin embargo, este juicio de posibilidad es un juicio objetivo, en tanto las peculiaridades individuales del autor no son consideradas; la posibilidad de la previsión del autor se mide según un parámetro objetivo y general, el del hombre cuidadoso ${ }^{34}$.

La conexión causal y teleológica debe distinguirse del juicio de valoración jurídica. Aquella establece si un suceso es propio del sujeto como su hecho, como su obra; el juicio jurídico relaciona el suceso imputado con la norma, valora el hecho ${ }^{35}$. Junto a este juicio teleológico sobre el hecho se formula un juicio normativo sobre el valor del hecho; junto al concepto de imputación objetiva entra el de la antijuridicidad objetiva, así como la imputación subjetiva se distingue de la antijuridicidad subjetiva ${ }^{36}$. La antijuridicidad objetiva supone entonces la imputación objetiva; pues, objeto de valoración jurídica no es el curso causal como tal, no el acontecimiento natural, sino el hecho, el suceso objetivamente imputable, por referirse a la voluntad como su principio rector ${ }^{37}$.

${ }^{29}$ Larenz, K., ob. cit., p. 75 y s.

${ }^{30}$ Larenz, K., ob. cit., p. 76.

${ }^{31}$ Larenz, K., ob. cit., p. 77, distingue entre la posibilidad formal y la posibilidad real, ob. cit., p. 78, siendo sin embargo determinante la posibilidad propia del sujeto.

${ }^{32}$ Larenz, K., ob. cit., p. 79.

33 Larenz, K., ob. cit., p. 81.

${ }^{34}$ Larenz, K., ob. cit., p. 84, en la omisión, por ejemplo, resulta determinante el poder de la voluntad de dominar el curso causal; la posibilidad de prever y evitar el resultado; la omisión es imputable en la medida en que la posibilidad de la acción omitida es una posibilidad propia de la voluntad, ob. cit., pp. 85 y ss.

${ }^{35}$ Larenz, K., ob. cit., p. 87.

${ }^{36}$ Larenz, K., ob. cit., p. 90.

${ }^{37}$ Larenz, K., ob. cit., p. 92. 
La peculiaridad individual y capacidad del sujeto no son todavía consideradas. Así en la previsión de consecuencias no se trata de la posibilidad de previsión de un autor determinado, sino de un hombre juicioso en la situación del autor. El suceso se le imputa como hecho, donde se considera el sujeto de imputación como persona abstracta y no según su individualidad concreta ${ }^{38}$. La imputación subjetiva es la expresión para la valoración individual del autor ${ }^{39}$.

\section{b) Primera formulación dogmática por Richard Honig}

La perspectiva desde la cual Honig desarrolla el concepto de imputación objetiva es, a diferencia del planteamiento de Larenz, netamente dogmática. De ahí que su análisis comience con la constatación de que la teoría de la relación de causalidad se encuentra en una profunda crisis. La discusión entre la teoría de la equivalencia de las condiciones y de la causalidad adecuada no se mantiene ya dentro del problema causal, sino que se ubica en los límites del concepto de causalidad como tal ${ }^{40}$. Si la teoría de la causalidad adecuada gana más terreno, es porque ya no es posible desconocer que en ciencia jurídica no se trata sólo de la comprobación de la relación de causalidad, sino más bien de un modo determinado de nexo entre acción y resultado que satisface las exigencias del ordenamiento jurídico ${ }^{41}$. Si se admite la posibilidad de selección y valoración entre las condiciones que provocan el resultado, entonces se traspasa el límite de un concepto de causalidad exclusivamente ontológico. En verdad, se trata de intentos por aclarar los presupuestos bajo los cuales la relación de causalidad entre acción y resultado puede servir de fundamento apto para el juicio jurídico-penal ${ }^{42}$. Desde que se constata que la acción es una condición necesaria para la realización del resultado, la pregunta de la causalidad ya está decidida ${ }^{43}$. Sin embargo, con este juicio sobre la relación fáctica entre acción y resultado no se decide aún si ese nexo es relevante para el ordenamiento jurídico. Luego del juicio causal tiene lugar un juicio independiente sobre la imputación objetiva, el cual responde la pregunta axiológica por la relevancia de la relación de causalidad para el ordenamiento jurídico ${ }^{44}$. Honig reconoce en el planteamiento de Larenz un fundamento filosófico plausible, sin embargo se propone desarrollar el concepto de imputación objetiva desde los principios generales de la teoría del Derecho ${ }^{45}$.

El juicio de imputación presupone exclusivamente una conducta humana en el sentido de una expresión de voluntad como punto de referencia del resultado. Por medio de la conducta humana, el hombre realiza sus fines al intervenir en los procesos

\footnotetext{
${ }^{38}$ Larenz, K., ob. cit., p. 94.

${ }^{39}$ Larenz, K., ob. cit., p. 99.

${ }^{40}$ Honig, R., FS Frank, p. 174.

${ }^{41}$ Honig, R., FS Frank, p. 175.

${ }^{42}$ Honig, R., FS Frank, p. 178.

${ }^{43}$ Honig, R., FS Frank, p. 178 y s.

${ }^{44}$ Honig, R., FS Frank, p. 179.

45 Honig, R., FS Frank, p. 181 y s.
} 
naturales, al someter la naturaleza a sus fines ${ }^{46}$. De ahí que el criterio para la imputabilidad del resultado sea la perseguibilidad objetiva (objektive Zweckhaftigkeit). Imputable es aquel resultado que puede ser pensado como puesto finalmente ${ }^{47}$. Se trata de un juicio objetivo, pues no se pronuncia sobre la relación psíquica del autor con el resultado. No se basa en el conocimiento actual y la voluntad del autor, sino más bien en sus capacidades potenciales. Se trata de la pregunta práctica por la perseguibilidad objetiva de la conducta $^{48}$. Esta se caracteriza adecuadamente con el concepto de dominabilidad del curso causal ${ }^{49}$. En consecuencia, la conducta humana que causa un resultado sólo es jurídicamente relevante, cuando ésta puede ser pensada como puesta finalmente en miras a la realización o evitación del resultado ${ }^{50}$.

Desde este punto de vista, puede abordarse la pregunta por la llamada "causalidad de la omisión”. Causalidad no es sólo una categoría lógica, sino también empírica; debe comprenderse como una relación de eficacia ${ }^{51}$. Ello traza una diferencia esencial entre la causalidad del hacer y la del no-hacer; pues, en la primera el hacer desencadena fuerzas, mientras que en la segunda el no-hacer sólo deja correr las fuerzas ${ }^{52}$. En relación al resultado, sólo puede hablarse de omisión cuando el autor lo podía prever y dominar, esto es, evitar. La pregunta determinante es entonces si el autor podía evitar el resultado, si le era posible, en vez de permanecer inactivo, realizar una actividad que impidiera la realización del resultado. Esta pregunta debe responderse afirmativamente, cuando el resultado en las condiciones dadas era previsible y evitar su realización mediante una actividad contrapuesta se ubicaba en el ámbito de dominio del autor, en otras palabras, cuando el no-hacer puede pensarse como puesto finalmente ${ }^{53}$. El planteamiento de la teoría de las condiciones, en orden a confirmar la relación de causalidad cuando la omisión no puede ser eliminada sin que el resultado caiga, se basa en el presupuesto implícito de que existe una omisión, esto es, un permanecer inactivo a pesar de la posibilidad de actividad. Pues sólo esta posibilidad le otorga al no-hacer el significado de una omisión. Una omisión y no el mero no-hacer es fundamento apto de la responsabilidad penal. No se trata entonces de una restricción de responsabilidad, sino de la explicación del fundamento de la responsabilidad. Sólo cuando un resultado es objetivamente imputable al permanecer inactivo, el no-hacer alcanza el significado de una omisión. "La imputabilidad del resultado es elemento constitutivo de la omisión penalmente relevante" 54 .

En opinión de Honig, la pregunta por la tipicidad no contiene una restricción de la responsabilidad, sino que determina el objeto de valoración y, con ello, el fundamento

\footnotetext{
${ }^{46}$ Honig, R., FS Frank, p. 182 y s.

${ }^{47}$ Honig, R., FS Frank, p. 184, con referencias a Larenz, Hegels Zurechnungslehre.

${ }^{48}$ Honig, R., FS Frank, p. 185.

${ }^{49}$ Honig, R., FS Frank, p. 187.

${ }^{50}$ Honig, R., FS Frank, p. 188.

${ }^{51}$ Honig, R., FS Frank, p. 189.

${ }^{52}$ Honig, R., FS Frank, p. 190.

${ }^{53}$ Honig, R., FS Frank, p. 192.

${ }^{54}$ Honig, R., FS Frank, p. 193.
} 
de la responsabilidad ${ }^{55}$. La conducta activa sólo tiene el significado de un hecho en el sentido de los tipos penales de resultado y así de un fundamento de responsabilidad, cuando el resultado, que sin la realización de la voluntad no habría tenido lugar, al mismo tiempo era objeto posible de la voluntad, alcanzable mediante un acto conforme a la voluntad ${ }^{56}$. Este punto de vista puede resultar fructífero también respecto del fundamento de la participación. En la medida en que la conducta humana sólo constituye fundamento penalmente relevante de responsabilidad, en tanto satisface el tipo, la asignación jurídico penal de la conducta a los diferentes tipos de participación depende de la perseguibilidad objetiva de la conducta en relación a la realización del tipo, esto es, de que la conducta a ser valorada como participación pueda ser vista como objetivamente final respecto de la realización del tipo y al mismo tiempo querida por el partícipe en esa perseguibilidad objetiva $^{57}$. Así es por ejemplo coautor aquel cuya conducta está dirigida en conjunto con otra a la realización del tipo; cómplice aquel cuya conducta sólo está dirigida al apoyo de la realización del tipo ejecutada por otro ${ }^{58}$.

\section{c) Segunda formulación dogmática por Claus Roxin}

La perspectiva de Roxin es también netamente dogmática. En este sentido, toma explícitamente como punto de partida el planteamiento de Honig. El fundamento propiamente jurídico no radica en la explicación de determinadas condicionantes, sino en la fijación de los parámetros según los cuales pueden imputarse ciertos resultados a una persona. Esta es antes que nada una pregunta de criterios de valoración, a los cuales se someten los datos empíricos ${ }^{59}$. En la medida en que la tarea de la dogmática jurídicopenal consiste en la imputación de resultados y ésta la hace depender de una infracción a las exigencias de la norma, es claro que una conducta que satisface las exigencias de deber del tipo, objetivamente no puede perseguir la producción del resultado típico. Si se realiza a pesar de ello el resultado típico, entonces no se trata de una obra del autor, sino de mera casualidad. Roxin delinea criterios concretos de imputación que implican el desarrollo del principio general de la perseguibilidad objetiva propuesto por Honig ${ }^{60}$.

El primero de estos criterios es la disminución del riesgo, esto es, el resultado no se imputa al autor, cuando su conducta estaba dirigida a disminuir la creación del riesgo en relación al afectado ${ }^{61}$. El segundo criterio es la creación de un riesgo jurídicamente relevante. Para su valoración, puede aplicarse el criterio de la previsibilidad objetiva, desarrollado en el ámbito de la imprudencia. Con este criterio, pueden resolverse también

\footnotetext{
${ }^{55}$ Honig, R., FS Frank, p. 195.

${ }^{56}$ Honig, R., FS Frank, p. 196 y s.

${ }^{57}$ Honig, R., FS Frank, p. 198 y s.

${ }^{58}$ Honig, R., FS Frank, p. 199.

59 Roxin, C., FS Honig, p. 133.

${ }^{60}$ Roxin, C., FS Honig, p. 135.

${ }^{61}$ Roxin, C., FS Honig, p. 136; posteriormente el mismo, Strafrecht. Allgemeiner Teil, Tomo I, 4. ed., Beck, München, 2006, $§ 11 \mathrm{~nm} .53$ y s. (en adelante: Strafrecht, T. I).
} 
los casos de desviación en el curso causal. Ejemplo: un sujeto sufre un atropello y luego es víctima de un accidente de tránsito en el camino al hospital, entonces la muerte no es imputable al primer causante ni como homicidio doloso ni como culposo, pues la realización del transporte vehicular, si bien conlleva un riesgo, éste no es jurídicamente relevante. En cambio, si un sujeto es empujado por otro con dolo homicida desde un puente y, contrariamente a lo esperado por éste, muere no ahogado, sino por un golpe en el pilar del puente, ello no cambia nada en la confirmación de un homicidio consumado doloso, pues el modo de ejecución elegido comporta desde un principio el riesgo de tal desenlace $^{62}$. Un tercer criterio consiste en el rebasamiento del riesgo permitido. Cuando el legislador permite correr riesgos en el funcionamiento de instalaciones peligrosas hasta un cierto límite, entonces la imputación puede recién fundamentarse en tanto la conducta del autor implica sobrepasar el riesgo permitido. Si este es el caso, entonces debe imputarse el resultado al sujeto actuante, y ello incluso cuando el resultado probablemente también se hubiere realizado en caso de una conducta exenta de errores ${ }^{63}$. Por ejemplo, en el caso conocido como de los pelos de cabra el fabricante entrega, con infracción de deberes reglamentarios, material no desinfectado a sus trabajadoras, de las cuales cuatro se contagian de una bacteria y mueren; el resultado es imputable a la conducta, aun cuando se compruebe que de haberse sujeto a las prescripciones reglamentarias pertinentes no se habría garantizado la eliminación de la bacteria ${ }^{64}$.

Como cuarto criterio de imputación Roxin propone el ámbito de protección de la norma. Este criterio proveniente del derecho civil y de carácter puramente normativo, cumple la función de abarcar los casos no comprendidos por los otros criterios, esto es, para casos en que el resultado se realiza como consecuencia de la producción de un riesgo jamás permitida, el cual sin embargo no se imputa, porque el legislador no quiere hacer responsable al sujeto actuante por ello ${ }^{65}$. Ejemplo: dos ciclistas conducen en la oscuridad uno tras otro sin luces y un tercero que viene en sentido contrario choca con el primer ciclista; el segundo ciclista no responde por el accidente, pues el deber de alumbrar que le alcanza no tiene el sentido de iluminar al primero. También las llamadas consecuencias tardías del hecho deberían resolverse en esta sede ${ }^{66}$. Asimismo, este criterio permite resolver los casos de afectaciones al cuerpo y la vida provenientes de intentos de rescate. Ejemplo: un desatento vigilante de niños en la piscina provoca un peligro y un tercero, al intentar rescatarlos, muere ${ }^{67}$. En aplicación de este criterio, no podría extenderse el ámbito de protección de la norma a personas adultas y responsables que buscan voluntariamente ayudar, pues éstas asumen un riesgo propio (Risikoabnabme) ${ }^{68}$.

\footnotetext{
${ }^{62}$ Roxin, C., FS Honig, p. 137; el mismo, Strafrecht, T. I, § 11 nm. 69 y s.

${ }^{63}$ Roxin, C., FS Honig, p. 138; el mismo, Strafrecht, T. I, \$11 nm. 65 y ss.

${ }^{64}$ Roxin, C., FS Honig, p. 139.

${ }^{65}$ Roxin, C., FS Honig, p. 140 y s.; el mismo, Strafrecht, T. I, $\$ 11$ nm. 84 y ss.

66 Roxin, C., FS Honig, p. 141.

67 Roxin, C., FS Honig, p. 142.

${ }^{68}$ Roxin, C., FS Honig, p. 143.
} 
El criterio del ámbito de protección de la norma constituye un parámetro que difiere del criterio de perseguibilidad objetiva propuesto por Honig. En el caso de los criterios antes reseñados, esto es, disminución del riesgo, falta de creación de un riesgo jurídicamente relevante y riesgo permitido, no es posible la imputación de resultado, sea que éste se provoque dolosa o culposamente. Las acciones realizadas en dichos casos no pueden estimarse como objetivamente dirigidas al resultado, aunque subjetivamente exista voluntad en ese sentido. En cambio, en los casos a resolver según el criterio del ámbito de protección de la norma, sí puede hacer una diferencia el que la acción se realice dolosa o culposamente. Cuando alguien mediante engaño dirige a un niño hacia una situación de alto peligro, con el fin de que el padre muera al tratar de rescatarlo, es posible imputar el resultado de muerte a título de homicidio doloso. Las consideraciones teleológicas que rigen para el principio de asunción de un riesgo no concurren en caso de que el resultado sea buscado ${ }^{69}$. Los tres primeros criterios son entonces concretización del principio de la perseguibilidad objetiva propuesto por Honig, mientras que el cuarto del ámbito de protección de la norma es un criterio de imputación independiente ${ }^{70}$. Del planteamiento expuesto se sigue que la finalidad no es un elemento necesario de una acción u omisión; aunque tampoco irrelevante. Determinante es, en todo caso, si el elemento subjetivo u objetivo se inserta en la imputación de acción, de injusto o de culpabilidad $^{71}$.

\section{Discusión CRÍtica del CONCEPTO DE IMPUTACión OBJETIVA}

Los tres planteamientos teóricos expuestos tienen en común una comprensión exclusivamente objetiva del juicio de imputación objetiva. Sin embargo, en la fundamentación de cada planteamiento se pone el acento en aspectos diferentes. Mientras que en los planteamientos de Larenz y de Honig la posición de la conducta juega un rol determinante para el juicio de imputación, Roxin parece responder esta pregunta fundamentalmente desde el resultado ${ }^{72}$. Esta diferencia de enfoque puede resultar significativa al momento de preguntarse por la relevancia que pueden tener aspectos subjetivos en el marco del juicio de imputación objetiva. Esta pregunta es ciertamente paradójica, pues desde un punto de vista sistemático es problemático valorar aspectos subjetivos en sede de un juicio que pretende emitirse de un modo objetivo y previo a la valoración propia de un

${ }^{69}$ Roxin, C., FS Honig, p. 144.
${ }^{70}$ Roxin, C., FS Honig, p. 146.
${ }^{71}$ Roxin, C., FS Honig, p. 146 y s.
${ }^{72}$ Frisch, "Zum gegenwärtigen Stand der Diskussion und zur Problematik der objektiven Zurechnungslehre”, en: Goltdammer's Archiv für Strafrecht, 2003, p. 721 y s., critica tanto el planteamiento de Honig como el de Larenz por concebir la imputación objetiva como una categoría prejurídica; destaca que tanto el criterio de la "perseguibilidad objetiva" como el de la "aptitud" para desencadenar el resultado se refieren a un problema de injusto de conducta, no de imputación de resultado (p. 736 y s.); sugiere, sin embargo, que el planteamiento de Honig pudo ser concebido en términos de una teoría de la conducta típica (notas 78 y 102). 
juicio de imputación subjetiva (dolo o culpa, culpabilidad) ${ }^{73}$. De ahí la relevancia de esta pregunta, pues ella puede obligar a una revisión del juicio de imputación objetiva como categoría de la dogmática penal.

\section{a) Limites de una comprensión exclusivamente objetiva del concepto}

La medida en que el juicio de imputación objetiva se comprende como valoración objetiva del hecho, sin considerar factores de conocimiento y capacidad del sujeto, parece variar entre los creadores de esta teoría. En Larenz, por ejemplo, resulta llamativo que, a renglón seguido de bautizar este juicio como imputación objetiva, subraye que acción es la unidad de la voluntad subjetiva y del ser exterior producido mediante ésta y, por tanto, que es casual todo aquello que es ajeno a la voluntad, aquello que no fue consciente, lo cual ocurre básicamente en los casos de error que menciona ${ }^{74}$. Justamente allí donde critica a Hegel por no haber abarcado la imprudencia, destaca que no sólo el saber es hecho de libertad, donde entonces la imputación parece indiscutible, sino también el no-saber puede ser imputado al sujeto, en tanto pueda ser considerado obra de su libertad ${ }^{75}$. Luego se refiere a la dialéctica de la imputación objetiva ${ }^{76}$ y reconoce que no es posible prescindir del momento subjetivo de la acción, sólo que debe ser entendido como una unidad objetiva. Recién en una reflexión más profunda sobre el momento subjetivo de la imputación, esto es, en sede de imputación subjetiva luego del juicio de imputación objetiva, se valoran las peculiaridades individuales del sujeto, sus capacidades, comprensión e intención individual ${ }^{77}$. Por su parte, Honig concibe el juicio sobre la perseguibilidad objetiva de la conducta como un juicio objetivo, en tanto no se pronuncia sobre la relación psíquica del autor con el resultado. Este juicio no se basa en el conocimiento actual y la voluntad del autor, sino más bien en sus capacidades potenciales $^{78}$. En su concepto, satisface las exigencias del juicio de imputación objetiva aquella conducta humana que puede ser pensada como puesta finalmente en miras a la realización o evitación del resultado ${ }^{79}$. La omisión sólo puede constituir fundamento de responsabilidad, cuando el resultado era previsible y su evitación era posible para el autor ${ }^{80}$. Lo mismo vale para la conducta activa, es decir, sólo puede configurar fundamento de responsabilidad, cuando el resultado, que sin la realización de la voluntad

${ }^{73}$ Sancinetti, M., "Observaciones sobre la teoría de la imputación objetiva", en: Teorías actuales en el Derecho penal, AA.VV., Ad-Hoc, Buenos Aires, 1998, p. 188, tilda de "al menos curioso" que una teoría que se concibe en términos objetivos pretenda abarcar aspectos subjetivos como los conocimientos especiales del autor; en su opinión, esta teoría sólo sirve de marco para el tipo subjetivo (pp. 191 y ss.).

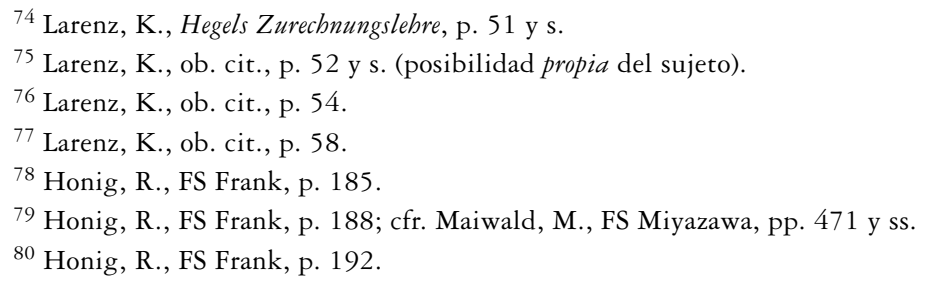


no habría ocurrido, era también objeto posible de la voluntad, alcanzable mediante un acto conforme a la voluntad ${ }^{81}$. Roxin, por último, señala que el criterio de imputación del ámbito de protección de la norma, que es estrictamente normativo y que diferencia su planteamiento de la propuesta de Honig, permite valorar de un modo distinto el resultado producido dolosamente del provocado sólo culposamente. En el ejemplo del sujeto que mediante engaño conduce a un niño a una situación de peligro, con el fin de que el padre muera al intentar rescatarlo, admite la posibilidad de imputación a título de dolo, restringiendo de esta manera el alcance del principio de asunción de riesgo, que entonces excluye siempre la imputación de resultado sólo en el hecho culposo ${ }^{82}$.

Estas diferencias de planteamiento conducen a la discusión de la relevancia que pueden alcanzar los aspectos subjetivos del conocimiento y la intención en el juicio de imputación objetiva. Al respecto, Bustos advierte, siguiendo a Armin Kaufmann ${ }^{83}$, que, por ejemplo, el criterio de disminución del riesgo supone una determinada intencionalidad, pues si, en el típico caso del sujeto que empuja a una persona para que una piedra no le caiga en la cabeza sino sólo en una parte no vital del cuerpo, la empuja con la intención de que le caiga en el brazo, el juicio de imputación puede variar. O si el sujeto la empuja para que el objeto le caiga en el hombro, teniendo la posibilidad de que no le dé en absoluto, para darse una pequeña venganza o como medio de corrección para el futuro ${ }^{84}$. En estos casos, la conducta de disminución del riesgo es objetivamente la misma, sólo cambia la intencionalidad en relación con el resultado, lo que hace variar el juicio de imputación. La aplicación de este criterio parece entonces suponer necesariamente un aspecto subjetivo ${ }^{85}$. Algo similar ocurre con la discusión sobre la relevancia del conocimiento especial. Ya Kaufmann critica, desde el finalismo, que el juicio sobre la creación del riesgo y su desvalorización jurídica no puede prescindir del saber del

${ }^{81}$ Honig, R., FS Frank, p. 196 y s.; con el concepto de imputación objetiva se sitúa la persona en primer plano, esto es, en su capacidad de tomar decisiones, que no son causalmente determinadas, Maiwald, M., FS Miyazawa, p. 477; Maiwald, ob. cit., pp. 472 y s., 479, manifiesta su preferencia por esta versión original de la teoría de la imputación objetiva, en tanto distingue claramente entre el objeto de la valoración, dado por el hecho objetivamente imputable, y los criterios conforme a los cuales se valora el hecho; es decir, en la versión de Honig, como en la de Larenz, el concepto de imputación objetiva sirve para delimitar el objeto de imputación, que ya no viene determinado por la causalidad, pero la valoración jurídica del mismo se produce en un momento posterior; Maiwald, ob. cit., pp. 474 y s., 477, critica a la versión actualmente dominante de la imputación objetiva, impulsada preponderantemente por Roxin, confundir esos niveles, al usar el juicio de imputación objetiva como criterio de valoración y no sólo para delimitar el objeto de imputación.

${ }^{82}$ Roxin, C., FS Honig, p. 144.

${ }^{83}$ Kaufmann, A., ADPCP 1985, p. 811 y s.

${ }^{84}$ Bustos, J., "Imputación objetiva: cuestiones metodológicas y sistemáticas", en: Obras Completas, ARA Editores, Lima 2004, Tomo II, p. 803 (en adelante: Imputación objetiva).

${ }^{85}$ Bustos, Imputación objetiva, p. 804. - Se ha intentado también una crítica interna a este criterio: Samson, E. "Imputación de resultado y riesgo (interrogatorio crítico a la teoría de la imputación objetiva)", en: Causalidad, riesgo e imputación, pp. 385 ss.; Sancinetti, M., "Principio de disminución del riesgo versus relevancia del disvalor de resultado en la teoría del ilícito”, en: www.indret.com 3/2008, sostiene que consecuencia de este criterio debiera ser que una decisión en sí razonable desde una perspectiva ex ante sigue siendo atípica, aunque no logre la reducción del riesgo o incluso termine por aumentarlo (p. 18 y s.). 
autor $^{86}$. En este sentido, Roxin parece conceder esta crítica, pues admite la posibilidad de imputación, por ejemplo, cuando alguien aconseja a otro dar un paseo, sabiendo que en el camino se esconde un homicida, ya que se crearía en este evento naturalmente un riesgo ${ }^{87}$. La valoración del conocimiento especial no sería, según Roxin, asistemática, pues, "en verdad (...), donde está presente, es un elemento constituyente del concepto de riesgo no permitido, que presupone ya el tipo objetivo. El conocimiento del autor debe incluirse en el juicio sobre la peligrosidad objetiva de su acción, pues la protección de bienes jurídicos sólo puede alcanzarse mediante la prohibición de acciones peligrosas, prohibición que a su vez sólo puede basarse en un juicio ex ante" 88 .

Lo cierto es que para una teoría que se comprende a sí misma como un juicio objetivo sobre la imputación de resultado, resulta difícil justificar la inclusión del conocimiento especial del autor en dicha valoración. En cambio, en la versión original del juicio de imputación objetiva, propuesta por Larenz, la inclusión de dicho aspecto no parece estar excluida de por sí. Para este autor, la imputación al hecho no depende de un juicio causal, sino de un juicio teleológico. El hecho no se determina por la relación de causalidad, sino por una relación distinta entre autor y hecho, en que éste aparece dominado por la voluntad: imputación al hecho significa relación del acontecimiento con la voluntad ${ }^{89}$. Tarea de la imputación objetiva es determinar si el acontecimiento se eleva sobre el reino de la mera casualidad y puede ser visto como un hecho propio del sujeto. La voluntad domina el acontecimiento natural y lo convierte en hecho propio, cuando el sujeto, mediante su capacidad de definir fines y de realizarlos, se sirve del curso causal, le da la dirección hacia un objetivo ${ }^{90}$. En este sentido, Larenz usa el concepto "causalidad de la voluntad", la que supone el momento del conocimiento, esto es, la capacidad del sujeto de prever el curso causal, y la capacidad de intervenir, en base a ese conocimiento, en el curso causal y darle la dirección buscada ${ }^{91}$. A partir de estas premisas, la imputación al hecho en el caso de un sujeto que desencadena un curso causal sabiendo cual va a ser el desenlace, no sería problemática, en tanto que difícilmente podría negarse la relación del acontecimiento con su voluntad y afirmarse simplemente que pertenece a la mera casualidad. Por su parte, para Honig el juicio de imputación objetiva se satisface, en tanto la conducta humana puede ser pensada como puesta finalmente en miras a la realización o evitación del resultado. Se trata entonces de un planteamiento basado en la evitabilidad del resultado, donde resulta menos problemático considerar el conocimiento

${ }^{86}$ Kaufmann, A., ADPCP 1985, p. 815 y s.; su postura, empero, de despojar el juicio de tipicidad objetiva de toda "desvalorización jurídica", el mismo, ob. cit., pp. 816 y ss., conduce a una imagen naturalista del injusto doloso como mera causalidad abarcada por el dolo, lo cual no resulta convincente; cfr. Frisch, W., "Imputación objetiva: estado de la cuestión”, en: Sobre el estado de la teoría del delito, Civitas, Madrid, 2000, p. 51 y s. (en adelante: Imputación objetiva).

${ }^{87}$ Roxin, C., Strafrecht, T. I, § $11 \mathrm{~nm} .56$.

${ }^{88}$ Roxin, C., ob. cit., $\S 11 \mathrm{~nm}$. 57 (destacado agregado); al respecto, a continuación 2.c.

${ }^{89}$ Larenz, K., Hegels Zurechnungslehre, p. 62 y s.

${ }^{90}$ Larenz, K., ob. cit., p. 67 y s.

${ }^{91}$ Larenz, K., ob. cit., p. 75 y s. 
especial como criterio de valoración ${ }^{92}$. Así, respecto del caso del sobrino que es enviado a la colina con el bosque de árboles altos en plena tormenta, Honig propone diferenciar lo que es mera casualidad del caso en que puede decirse que el autor se sirve de la fuerza natural de la tormenta, por ejemplo, cuando es dable observar que la tormenta es habitual en esa época del año y justamente allí tiene lugar, por lo que es posible contar con repeticiones ${ }^{93}$. En todo caso, es claro que el sujeto que conoce de una determinada circunstancia objetivamente peligrosa para la víctima, puede evitar la creación del riesgo para ella ${ }^{94}$. Otra cosa es que deba hacerlo.

\section{b) Significado de la distinción entre creación desaprobada del riesgo e imputación de resultado}

El problema que plantea la plausibilidad de considerar aspectos subjetivos ya en sede de imputación objetiva obliga a una reflexión sobre la viabilidad de concebir este juicio exclusivamente en términos de imputación objetiva del resultado. Dicho de otra manera, es preciso reflexionar en torno a la necesidad de un juicio de valoración previo a la pregunta estricta por la imputación del resultado. En este sentido, Bustos señala, en relación al criterio de disminución del riesgo, que las interacciones son las riesgosas y no los resultados. De ahí que dicho criterio tematice un problema de determinación de la situación típica, cuestión previa a la imputación de resultado ${ }^{95}$. Lo mismo ocurre con el criterio del riesgo permitido. Si una actividad riesgosa es tolerada, entonces lo es antes de que se haya causado cualquier resultado. Dicho criterio atañe también, según

92 Cfr. Köhler, M., Strafrecht. Allgemeiner Teil, Springer, Berlin, 1997, p. 144 y s.: la conducta debe contener la posibilidad real concreta de lesión típica, según una base de juicio objetivo que comprende todas las leyes disponibles de la experiencia, todos los hechos objetivamente reconocibles, incluidos los abarcados por el conocimiento especial de alguno de los potenciales sujetos de acción; objetivamente no relevante para la prohibición es sólo la casualidad externa; Jakobs, G., Studien, pp. 39 y ss., elabora el concepto de evitabilidad en su escrito de habilitación.

${ }^{93}$ Honig, R., FS Frank, p. 186; sin embargo, Honig niega la imputación de resultado en un caso de conocimiento especial: A motiva a B para que emprenda un crucero, a pesar de que sabe que la empresa naviera que ofrece ese crucero, también usa barcos no aptos, y justamente el barco que lleva a $\mathrm{B}$ se hunde a consecuencia de esa falla (p. 186 y s.).

${ }^{94}$ Kindhäuser, U., "Der subjektive Tatbestand im Verbrechensaufbau. Zugleich eine Kritik der Lehre von der objektiven Zurechnung”, en: Goltdammer's Archiv für Strafrecht, 2007, p. 454 y s., comparte el modelo de imputación propuesto por Honig, en tanto el juicio de imputación objetiva determina no el objeto sino el fundamento de la responsabilidad, al esclarecer la "evitabilidad final de la realización típica", donde entonces el saber del sujeto necesariamente debe ser incluido: "Saber suficiente es para la evitabilidad del resultado por acción (en caso de mandato) o por omisión (en caso de prohibición) no menos necesario que la conducta externa causal"; critica sin embargo el sentido de un juicio de imputación objetiva según la figura del hombre abstracto previo a la imputación subjetiva que considera al destinatario concreto de la norma (456 y s.); cfr. el mismo, "Risikoerhöhung und Risikoverringerung", en: Zeitschrift für die gesamte Strafrechtswissenschaft, 2008, p. 482.

95 Bustos, J., Imputación objetiva, p. 804; Manual de Derecho Penal, Parte General, 4. ed., PPU, Barcelona, p. 297 (en adelante: Manual). 
Bustos, a la determinación de la situación típica y no a la imputación de resultado ${ }^{96}$. En cuanto al criterio del fin de protección de la norma, aplicable al caso de los ciclistas, se observa que este busca impedir aumentos de riesgos de las acciones propias, por lo que la acción del segundo ciclista no puede ser asignada al ámbito situacional, tratándose entonces de un problema de determinación de la situación típica y no de imputación de resultado 97 . El juicio de tipicidad es, para Bustos, un juicio de atribución de una situación real a la situación descrita por el tipo legal, por tanto, un juicio valorativo ${ }^{98}$. Para configurar el injusto, es preciso empero completar el desvalor de acto, dado con dicho juicio de atribución, con el desvalor de resultado ${ }^{99}$, donde pertenece la imputación de resultado ${ }^{100}$.

En la misma dirección, Frisch distingue sistemáticamente entre la creación jurídicamente desaprobada de un riesgo y la imputación de resultado ${ }^{101}$. La primera constituye

96 Bustos, J., Imputación objetiva, p. 805; Manual, p. 297 y s.

97 Bustos, J., Imputación objetiva, p. 805 y s.; Manual, p. 298; lo mismo ocurre con los principios de autonomía de la víctima o de pertenencia al ámbito de responsabilidad ajena, el mismo, Imputación objetiva, p. 806 y s. - Esta reconstrucción de la categoría de la imputación objetiva es fundamentada también en Bustos, J., El delito culposo, Ed. Jurídica, Santiago, 1995, notas 17, 28 y 44.

${ }^{98}$ Bustos, J., Imputación objetiva, p. 808 y s.; sobre la tipicidad como juicio de atribución el mismo, en: Bases críticas de un nuevo derecho penal, Ed. Conosur, Santiago, 1994, p. 68 y s.; Manual, pp. 254 y ss.

99 Bustos, J., junto con Hormazábal, H., Lecciones de Derecho penal, publicado también en: Obras Completas, ARA Editores, Lima, 2004, Tomo I, pp. 785 y ss., señalan que el juicio de tipicidad es emitido por el juez y consiste en la atribución de la situación concreta al tipo abstracto definido por el legislador; en este juicio, cumple un rol fundamental el desvalor de acto, entendido como contravención de la norma de prohibición o mandato; dicho desvalor de acto se determina, empero, no subjetivamente, sino en base a un juicio objetivo, desde el bien jurídico, y ex ante, esto es, la conducta debe comportar un riesgo o peligro para el bien jurídico; Bustos, J.; Hormazábal, H., ob. cit., pp. 792 y ss., explican que para configurar el injusto no es suficiente el desvalor de acto verificado con el juicio de tipicidad, sino que es preciso constatar su "efecto social", el desvalor de resultado; este se verifica en un juicio distinto y posterior, que es la antijuridicidad, la cual ya no se define sólo negativamente por la ausencia de causas de justificación, sino que positivamente; su contenido material viene dado por el bien jurídico: "contravención del hecho típico con todo el ordenamiento jurídico en virtud de una afectación efectiva del bien jurídico" (p. 793); donde se constata, conforme a un juicio objetivo y ex post, que la afectación del bien jurídico sea la "plasmación" de la realización típica.

${ }^{100}$ Bustos, J., Imputación objetiva, pp. 811 y ss.; consecuencia lógica de la tesis que el desvalor de resultado pertenece sistemáticamente a la antijuridicidad, da contenido al juicio de antijuridicidad, es la ubicación de la imputación objetiva de resultado en sede de antijuridicidad; es decir, la tesis no consiste en sostener directamente que la imputación objetiva se ubica en sede de antijuridicidad, sino que, al ubicar el desvalor de resultado constitutivo de una parte del injusto en la antijuridicidad, entonces (sólo) los criterios de imputación objetiva de resultado se tratan en esa sede, mientras que los demás criterios de imputación objetiva, como la disminución del riesgo, el riesgo permitido, autonomía de la víctima, etc., se replantean en términos de criterios para la determinación de la situación típica, del juicio de tipicidad, cuyo contenido de injusto viene dado fundamentalmente por el desvalor de acto; esto se observa claramente cuando Bustos, El delito culposo, pp. 66 y ss. aplica criterios de imputación objetiva a la imprudencia, distinguiendo aquellos relevantes en sede de tipicidad, como la disminución del riesgo, el riesgo permitido, fin de protección de la norma, de los determinantes en sede de antijuridicidad, como la realización del comportamiento típico en el resultado jurídico, conducta alternativa conforme a derecho, ob. cit., pp. 74 y ss.

${ }^{101}$ Frisch, W., Comportamiento típico e imputación del resultado, Marcial Pons, Madrid, 2004, pp. 51 y ss., 65 y ss., 74 y ss. (en adelante: Comportamiento típico). 
el núcleo de la conducta típica y presupone la vulneración de la norma de conducta subyacente al tipo $^{102}$. Requiere un juicio de valoración sobre el conflicto entre la libertad de acción y el interés en la protección de bienes jurídicos. Para resolver este conflicto, deben considerarse los criterios de idoneidad, necesidad y adecuación, extraídos del principio de proporcionalidad, esto es, la desaprobación jurídica de la creación del riesgo debe ser un medio idóneo, necesario y proporcional para conferir protección al bien jurídico ${ }^{103}$. La perspectiva desde la cual se determina la observancia de la norma en relación a la producción del riesgo es un juicio ex ante ${ }^{104}$. En contraste con la determinación de la conducta típica, la imputación de resultado tiene un fundamento autónomo, que surge de la exigencia de realización de resultado en los tipos penales ${ }^{105}$. El fundamento material radica en la limitación de la sanción penal a determinadas infracciones de normas de conducta, esto es, las que conducen efectivamente a la realización del resultado. Se trata entonces de una exigencia de la norma de sanción distinta a la infracción misma de la norma de conducta ${ }^{106}$. A diferencia de ésta, la perspectiva desde la cual se determina la imputación de resultado es un juicio ex post ${ }^{107}$. La imputación de resultado se determina básicamente según un criterio positivo, cual es el nexo de realización entre conducta típica y resultado, y un criterio negativo, que excluye dicha imputación en los casos de conducta alternativa conforme a derecho ${ }^{108}$.

\section{c) Conocimiento especial e infracción de la norma de conducta}

En esta versión de la teoría de la imputación objetiva, resulta plausible observar los conocimientos especiales del autor para la desvaloración jurídica del riesgo producido. Esto resulta sistemáticamente más difícil en un planteamiento basado exclusivamente en la imputación objetiva de resultados ${ }^{109}$. El argumento de Roxin en orden a que la

102 Frisch, W., Comportamiento típico, pp. 77 y ss., 85 y ss.

103 Frisch, W., ob. cit., pp. 89 y ss.

${ }^{104}$ Frisch, W., ob. cit., p. 111.

105 Aquí es posible observar una diferencia sistemática con el planteamiento de Bustos, pues la realización del resultado es un elemento del tipo, sólo que no fundamenta el desvalor de conducta; es decir, de los diferentes elementos del tipo, la conducta típica fundamenta el injusto de conducta, mientras que la realización en el resultado es sólo una exigencia adicional del tipo, presupuesto de la norma de sanción distinto a la infracción de la norma de conducta.

${ }^{106}$ Frisch, W., ob. cit., pp. 541 y ss., 547 y ss. (en atención a los fines de la pena); distingue entre norma de conducta y norma de sanción Jakobs, G., Studien, p. 10 y s.

${ }^{107}$ Frisch, W., ob. cit., p. 550 y s.

${ }^{108}$ Frisch, W., ob. cit., pp. 551 y ss., 561 y ss.

109 Reyes, Y., ADPCP 1992, pp. 952 y ss., parte de una concepción valorativa del injusto, en que la imputación objetiva depende de las expectativas de comportamiento exigibles según el rol de cada persona; eventualmente puede serle exigida la activación de sus conocimientos o capacidades especiales, lo cual depende siempre de que en virtud de una posición de garante exista para ella un deber de actuación (p. 954); estos aspectos pertenecen sistemáticamente a la dimensión del injusto, mientras que la subjetividad como hecho psíquico individual forma parte de la culpabilidad (p. 955: incluso el aspecto cognoscitivo del dolo pertenecería a la imputación objetiva); así, el sujeto que conoce la condición de hemofílico de su vecino, está 
protección de bienes jurídicos se alcanza mediante la prohibición de acciones peligrosas y que ésta sólo puede juzgarse desde una perspectiva ex ante, por lo que los conocimientos especiales deben incluirse en el juicio sobre la peligrosidad objetiva de la acción, resulta insuficiente ${ }^{110}$. Por cierto que la protección de bienes jurídicos se logra mediante la prohibición de conductas. Sin embargo, que la infracción de la prohibición deba determinarse según un juicio ex ante requiere una justificación, que Roxin no ofrece. Menos justificada es la afirmación de que los conocimientos especiales son relevantes para determinar la peligrosidad objetiva de la acción. Un aspecto subjetivo como el conocimiento de una determinada circunstancia no puede volver una acción objetivamente más peligrosa. La creación de un riesgo para la integridad de un bien jurídico es objetivamente la misma, con o sin conocimiento de las circunstancias que lo fundamentan. No obstante, Roxin lleva razón al señalar que la prohibición sólo puede basarse en un juicio ex ante. Esto, sin embargo, difícilmente puede ser explicado sin recurrir a la dimensión de la norma ${ }^{111}$. El sentido de la norma no puede ser otro que influir sobre la conducta previo a la creación del riesgo. Ésta sólo puede evitarse, en la medida en que el mensaje de la norma alcanza a su destinatario en el momento previo ${ }^{112}$. Por eso, la infracción de la norma de conducta debe determinarse conforme a un juicio ex ante. En esta perspectiva, son relevantes no sólo las circunstancias objetivas fundantes del riesgo, sino también el conocimiento que el autor puede tener de una determinada circunstancia ${ }^{113}$. El contenido de la norma de conducta puede variar frente a la presencia de conocimiento especial, por lo que la determinación de su infracción también. Esto significa que este conocimiento

obligado a no propinarle golpes que sean peligrosos para dicha persona (p. 956); este planteamiento resulta interesante como propuesta sistemática, deja, sin embargo, una duda en su fundamentación al identificar sin más rol con posición de garante (así, p. 963), pues en el ejemplo del vecino hemofílico no se vislumbra ninguna posición de garante de la cual pueda surgir una expectativa de comportamiento que impida aún una lesión levísima eventualmente causante de muerte.

${ }^{110}$ Más consecuente Jakobs, G., "La imputación objetiva, especialmente en el ámbito de las instituciones jurídico-penales del 'riesgo permitido', la 'prohibición de regreso' y el principio de confianza”, en: Estudios de Derecho penal, Civitas, Madrid, 1997, p. 209, respecto del ejemplo del estudiante de biología que trabaja como garzón y reconoce en una ensalada que tiene que servir trozos de una planta venenosa: a un rol general corresponden tan sólo conocimientos generales, no especiales; en cambio, si el autor introduce por su cuenta el conocimiento especial, éste queda incorporado a su rol, en el ejemplo, si el estudiante toma la planta venenosa de la ensalada y la sirve a su tío con el objeto de poner fin a sus días (p. 214); cfr. el mismo, Strafrecht, AT 7/49 y ss.; distinta valoración del problema parece tener Jakobs, en Studien, p. 55 y s.

111 "Bautizo normas aquellas prescripciones jurídicas, porque el delincuente sólo puede contravenir aquella frase que le prescribe la regla de su conducta” Binding, K., Die Normen und ibre Übertretung, 4. ed., Scientia Verlag, Leipzig, 1922, Tomo I, p. 7 (también, pp. 45, 51 y ss., 97 y ss.).

${ }^{112}$ En este sentido, Mir Puig, S., "Sobre lo objetivo y lo subjetivo en el injusto", en: El Derecho penal en el Estado social y democrático de derecho, pp. 182 y ss., aunque desde una concepción altamente psicologizante (p. 184: la prohibición se dirige a la "mente" del ciudadano), donde la voluntad se define como “... la orden mediante la cual el cerebro activa los músculos dando lugar a una determinada conducta, consciente de su significado" (p. 185).

113 Así lo reconoce Frisch, W., Imputación objetiva, p. 56 y s.; recientemente Freund, G., Strafrecht. Allgemeiner Teil, 2. ed., Springer, Berlin, 2009, § 2 nm. 15. 
es relevante frente a la norma de conducta y, por tanto, puede ser valorado al momento de determinar la infracción de la misma ${ }^{114}$.

Si se parte de la premisa de que la imputación objetiva de resultado supone previamente la vulneración de una norma de conducta y que esta a su vez requiere una valoración del conflicto entre libertad de acción e interés en la protección de bienes jurídicos, entonces este juicio exige la ponderación de intereses en juego, en definitiva la delimitación entre esferas de libertad ${ }^{115}$. De esta manera, el juicio sobre el carácter prohibido de la conducta no se emite unilateralmente, considerando de antemano preponderante el interés en la protección de bienes jurídicos o el interés en la vigencia de la libertad, sino observando ambos intereses en juego. Se trata de ponderar el interés de la sociedad en la realización de la acción con la magnitud del peligro que comporta para bienes jurídicos, de tal modo que una conducta peligrosa sólo puede mantenerse no prohibida, en tanto su cualidad ampliadora de la libertad vuelve tolerable los riesgos asociados a ella ${ }^{116}$. Desde este punto de vista, implicaría una restricción de la libertad difícilmente soportable exigir la obtención activa de conocimientos, por ejemplo, de parte del poseedor de un vehículo que verifique el estado de los frenos antes de cada uso del mismo. Esta exigencia implicaría una carga que no estaría en una relación adecuada con la ganancia en seguridad que se obtendría. Sin embargo, el juicio varía cuando en el ejemplo el poseedor ya tiene un conocimiento positivo sobre un desperfecto

${ }^{114}$ Greco, L., “Das Subjektive an der objektiven Zurechnung: Zum 'Problem' des Sonderwissens”, en: ZStW 2005, pp. 534 y ss., propone una justificación de la consideración de los conocimientos especiales en sede de imputación objetiva basada en una concepción político-criminal del derecho penal -en el sentido de Roxin, Kriminalpolitik und Strafrechtssystem, De Gruyter, 1973, pp. 7 y ss.-, según la cual la construcción del sistema se supedita a las valoraciones político-criminales y no a categorías previas a éstas; en este sistema teleológico del derecho penal, las categorías se definen según su función político-criminal, siendo fin del tipo objetivo la determinación abstracta de los límites de lo externamente permitido y prohibido (p. 537; nota 99: la determinación concreta de lo permitido y prohibido se produce en sede de antijuridicidad, donde son ponderados y valorados los intereses concretos en juego); a la luz de esta tarea político-criminal del tipo objetivo puede ser necesario considerar los conocimientos y otros aspectos subjetivos, en tanto sean relevantes para determinar los límites de lo externamente prohibido, previo a la imputación de dolo o culpa en sede de tipo subjetivo (p. 537 y s.); más allá de la discusión epistemológica sobre la difícil relación entre políticacriminal y sistema del derecho penal, este planteamiento adolece de un uso indistinto de los conceptos de tipo y norma, cuando se trata de dos categorías diferentes; el tipo sólo describe un hecho -matar, lesionar, sustraer, etc.-, cuya realización es un presupuesto (fundamental) de punibilidad; la determinación de los límites de lo prohibido no viene dada directamente por el tipo, sino que por la norma que se deduce de éste; de ahí que el presupuesto fundamental del juicio de tipicidad, de la "imputación al tipo", sea la infracción de la norma, cuya determinación exige un juicio en concreto previo al propio de la antijuridicidad; al respecto, últimamente Mir Puig, S., "Norm, Bewertung und Tatbestandsunwert. Zum Verhältnis von Tatbestand und Norm”, en: Festschrift für Rolf Dietrich Herzberg, Mohr Siebeck, Tübingen, 2008, pp. 55 y ss.: la norma primaria (norma de conducta) es un imperativo que presupone una valoración negativa de la realización típica, la que no decae por la concurrencia de causas de justificación (pp. 66 y ss.; nota 28: que expresan una valoración diferente, un juicio de valor opuesto a la valoración de la norma).

115 Pues, en un Derecho penal liberal la protección de bienes jurídicos se justifica sólo en tanto sirven como presupuestos para el ejercicio de la libertad.

116 Últimamente Murmann, U., "Zur Berücksichtigung besonderer Kenntnisse, Fähigkeiten und Absichten bei der Verhaltensnormkonturierung”, en: Festschrift für Herzberg, p. 129 y s. 
del vehículo, pues entonces sí se legitima la restricción de su libertad. En ese caso, los riesgos asociados al uso del vehículo serían para el poseedor fácilmente evitables. El fundamento para mantener el carácter no prohibido de la misma conducta en ausencia de conocimiento especial decae. La ponderación de los peligros asociados a la conducta con la ganancia para la libertad de acción que se obtiene mediante el uso del vehículo se deslinda en este caso en perjuicio del poseedor del mismo ${ }^{117}$. La restricción de su libertad no parece en este caso desproporcionada, por lo que una actuación del sujeto a pesar del conocimiento positivo implica una infracción de la norma de conducta que fundamenta la imputación.

\section{VALORACIÓN FINAL}

El origen de la teoría de la imputación objetiva en Larenz se vincula a una concepción del hecho como unidad de acción y consecuencia, dominada por la voluntad, que en esa medida supera la relación de causalidad. La versión propuesta por Honig se construye básicamente sobre el concepto de evitabilidad del resultado, que fundamenta la responsabilidad tanto en la acción como en la omisión. Para ambas versiones, resulta determinante la medida en que la conducta está, por su relación con la voluntad, inclinada hacia la realización del resultado. Metodológicamente, ambas versiones de la teoría se comprenden en términos objetivos y, al menos en el caso de Larenz, como una categoría previa a la valoración jurídica. Roxin concibe también esta teoría en términos exclusivamente objetivos, pero al mismo tiempo construida sobre la base de criterios normativos. Esta versión de la teoría, a diferencia de los dos originales, es menos consistente con la

${ }^{117}$ Murmann, U., ob. cit., p. 130 y s.- Greco, L., ZStW 2005, pp. 548 y ss., sostiene que el conocimiento especial es relevante para emitir el juicio de peligro desde la perspectiva de la protección a los bienes jurídicos: "Existe un peligro cuando la lesión o puesta en peligro de un bien jurídico ex ante no es completamente improbable para la figura objetiva del hombre medio o para el autor concreto que dispone de conocimientos especiales" (p. 549); la consideración de intereses opuestos a la protección de bienes jurídicos como p.ej. la libertad de acción no es relevante para el juicio de peligro, sino que sólo en un nivel posterior del juicio sobre el carácter (no) permitido del peligro, donde se decide definitivamente sobre la tipicidad objetiva; esto conduce a la afirmación de que la consideración de conocimientos especiales no implica una carga para el autor, en tanto los tenga previamente, sino que al contrario limita el juicio de peligro en el caso en que para la figura objetiva media exista un peligro, pero para el autor en posesión de conocimientos especiales la conducta no sea peligrosa (ejemplo: si el cocinero cree y cualquiera en su lugar creería que el hongo es venenoso, pero el mozo estudiante de biología se da cuenta por sus conocimientos especiales que es inocuo), caso en el cual la consideración de conocimientos especiales opera limitando y no ampliando la punibilidad; el problema de esta tesis radica justamente en su unilateralidad, esto es, que al adoptar como determinante el "principio" de protección a los bienes jurídicos necesariamente debe optar por la relevancia de los conocimientos especiales en el juicio de peligro; desde esa perspectiva, sin embargo, no queda claro por qué este juicio debe emitirse conforme a un punto de vista ex ante; si se trata de protección a los bienes jurídicos, entonces también circunstancias objetivas que influyen en la lesión o puesta en peligro del bien jurídico, determinadas conforme a un juicio ex post, debieran ser relevantes (ej.: el mozo estudiante de biología se da cuenta de lo venenoso del hongo, pero al servir la ensalada el cliente, por ser médico, se percata también de ello, evitando así su propia muerte). 
inclusión de aspectos subjetivos en el juicio de imputación objetiva. En las versiones más modernas de esta teoría, como las de Bustos o Frisch, la consideración de aspectos subjetivos resulta menos problemática, en la medida en que ambos acuñan un filtro previo a la pregunta estricta por la imputación de resultado, concebido en términos altamente normativos.

\section{BiBLIOGRAFÍA}

Binding, Karl, Die Normen und ibre Übertretung, 4. ed., Scientia Verlag, Leipzig, 1922, Tomo I.

Bustos, JuAn, Manual de Derecho Penal, Parte General, 4. ed., puesta al día por Hernán Hormazábal, PPU, Barcelona, 1994.

Bustos, Juan, Bases críticas de un nuevo Derecho penal, ConoSur, Santiago, 1994.

Bustos, Juan, El delito culposo, Ed. Jurídica, Santiago, 1995.

Bustos, JuAn, “Imputación objetiva: cuestiones metodológicas y sistemáticas”, en: Obras Completas, ARA Editores, Lima 2004, Tomo II.

Bustos, Juan; Hormazábal, Hernán, Lecciones de Derecho penal, en: Obras Completas, ARA Editores, Lima, 2004, Tomo I.

Freund, Georg, Strafrecht. Allgemeiner Teil, 2. ed., Springer, Berlin, 2009.

Frisch, WolfGang, "Imputación objetiva: estado de la cuestión", en: Sobre el estado de la teoría del delito, (AA.VV.), Civitas, Madrid, 2000.

Frisch, Wolfgang, "Zum gegenwärtigen Stand der Diskussion und zur Problematik der objektiven Zurechnungslehre”, en: Goltdammer's Archiv für Strafrecht, 2003.

Frisch, Wolfgang, Comportamiento típico e imputación del resultado, Pons, Madrid, 2004.

Greco, Luis, “Das Subjektive an der objektiven Zurechnung: Zum 'Problem' des Sonderwissens”, en: Zeitschrift für die gesamte Strafrechtswissenschaft, 2005.

Honig, Richard, "Kausalität und objektive Zurechnung”, en: Festgabe für Reinhard von Frank, Hegler, A. (coord.), Scientia Verlag, Tübingen, 1930, Tomo I; traducción reciente "Causalidad e imputación objetiva", en: Sancinetti, M. (comp.), Causalidad, riesgo e imputación. 100 años de contribuciones críticas sobre imputación objetiva y subjetiva, Hammurabi, Buenos Aires, 2009, pp. 105 y ss.

Jakobs, GüNTHer, Studien zum fahrlässigen Erfolgsdelikt, Walter de Gruyter, Berlin, 1972.

Jakobs, GÜNTHer, Strafrecht, Allgemeiner Teil, 2. ed., Walter de Gruyter, Berlin, 1993.

JAKOBS, GÜNTHER, "La imputación objetiva, especialmente en el ámbito de las instituciones jurídico-penales del 'riesgo permitido', la 'prohibición de regreso' y el principio de confianza", en: Estudios de Derecho penal, Civitas, Madrid, 1997.

Kaufmann, Armin, “‘Atribución objetiva', en el delito doloso?”, en: Anuario de Derecho Penal y Ciencias Penales, Tomo XXXVIII, Septiembre-diciembre 1985.

KINDHÄUSER, URs, "Der subjektive Tatbestand im Verbrechensaufbau. Zugleich eine Kritik der Lehre von der objektiven Zurechnung”, en: Goltdammer's Archiv für Strafrecht, 2007.

KINDHÄUSER, URS, "Risikoerhöhung und Risikoverringerung", en: Zeitschrift für die gesamte Strafrechtswissenschaft, 2008; traducción "Incrememto del riesgo y disminución del riesgo", en: Sancinetti, M. (comp.), Causalidad, riesgo e imputación. 100 años de contribuciones críticas sobre imputación objetiva y subjetiva, Hammurabi, Buenos Aires, 2009, pp. 573 y ss.

KöHLer, Michael, Strafrecht. Allgemeiner Teil, Springer, Berlin, 1997.

LaRenZ, Karl, Hegels Zurechnungslehre und der Begriff der objektiven Zurechnung, Dissertation, Göttingen, 1927. 
Maiwald, Manfred, "Zur strafrechtssystematischen Funktion des Begriffs der objektiven Zurechnung”, en: Festschrift für Koichi Miyazawa, Kühne, H.H. (coord.), Nomos, BadenBaden, 1995.

Mir Puig, Santiago, "Sobre lo objetivo y lo subjetivo en el injusto", en: El Derecho penal en el Estado social y democrático de derecho, Ed. Ariel, Barcelona, 1994.

Mir Puig, Santiago, "Norm, Bewertung und Tatbestandsunwert. Zum Verhältnis von Tatbestand und Norm", en: Festschrift für Rolf Dietrich Herzberg, Putzke, H. (coord.), Mohr Siebeck, Tübingen, 2008

Murmann, Uwe, "Zur Berücksichtigung besonderer Kenntnisse, Fähigkeiten und Absichten bei der Verhaltensnormkonturierung”, en: Festschrift für Rolf Dietrich Herzberg, Putzke, H. (coord.), Mohr Siebeck, Tübingen, 2008.

Reyes A., Yesid, "Fundamentos teóricos de la imputación objetiva", en: Anuario de Derecho Penal y Ciencias Penales, Tomo XLV, 1992.

Roxin, Claus, Kriminalpolitik und Strafrechtssystem, De Gruyter, Berlin, 1973.

Roxin, Claus, "Gedanken zur Problematik der Zurechnung im Strafrecht", en: Festschrift für Richard M. Honig, Otto Schwartz \& Co., Göttingen, 1970; traducción "Reflexiones sobre la problemática de la imputación en el Derecho penal”, en: Problemas básicos del Derecho penal, Reus, Madrid, 1976, pp. 128 ss.

Roxin, Claus, Strafrecht. Allgemeiner Teil, 4. ed., Beck, München, 2006, Tomo I.

SAMSON, ERICH, "Imputación de resultado y riesgo (interrogatorio crítico a la teoría de la imputación objetiva)", en: Sancinetti, M. (comp.), Causalidad, riesgo e imputación. 100 años de contribuciones críticas sobre imputación objetiva y subjetiva, Hammurabi, Buenos Aires, 2009.

Sancinetti, Marcelo A., "Observaciones sobre la teoría de la imputación objetiva”, en: Teorías actuales en el Derecho penal (AA.VV.), Ad-Hoc, Buenos Aires, 1998.

Sancinetti, Marcelo A., "Principio de disminución del riesgo versus relevancia del disvalor de resultado en la teoría del ilícito", en: www.indret.com 3/2008, Barcelona. 